\title{
Perawatan Ortodontik Inkonvensional Gigi Atas Berjejal Dengan Keberadaan Kista
}

\author{
Timothy Soewito *, Darmawan Sutantyo**, dan Cendrawasih A Farmasyanti \\ *Program Studi Ortodonsia PPDGS Fakultas Kedokteran Gigi Universitas Gadjah Mada \\ **Bagian Ortodonsia Fakultas Kedokteran Gigi Universitas Gadjah Mada \\ *JI Denta no 1 Sekip Utara Yogyakarta, tim_lim8@yahoo.com
}

\begin{abstract}
ABSTRAK
Keberadaan kista dapat menghambat perawatan ortodontik konvensional yang diberikan pada pasien. Tujuan artikel ini adalah menyajikan laporan kasus perawatan ortodontik alternatif seorang pasien perempuan berusia 17 tahun dengan kondisi gigi atas berjejal berat dan kista jinak di antara gigi insisivus lateral dan kaninus kiri atas. Setelah menetapkan diagnosis ortodontik, perawatan pertama yang dilakukan adalah pengangkatan kista. Kista dikirim untuk biopsi dan didiagnosis sebagai kista jinak. Orang tua dan pasien memutuskan untuk mencabut gigi insisivus lateral atas setelah mengetahui bahwa gigi insisivus lateral kiri atas nekrosis. Setelah gigi dicabut, bracket ortodontik dipasang di gigi bawah pasien. Tiga bulan kemudian, bracket ortodontik dipasang di gigi atas pasien. Kondisi gigi atas yang berjejal terkoreksi dan kaninus atas menggantikan posisi insisivus lateral. Saat ini, perawatan aktif masih dilanjutkan dan terpasang bracket ortodontik dengan elastik kelas III pada pasien. Kesimpulan artikel ini adalah pendekatan perawatan ortodontik inkonvensional dapat menjadi pertimbangan ketika ditemukan hambatan seperti adanya kista. Pasien dan orang tua harus diberi informasi mengenai konsekuensi perawatan sebelum perawatan dimulai.

Maj Ked Gi. Juni 2013;20(1): 99 - 104.
\end{abstract}

Kata kunci: Gigi berjejal, gigi atas, kista jinak, perawatan ortodontik, inkonvensional

\begin{abstract}
Unconventional Orthodontic Treatment for Upper Teeth Crowding with Benign Cyst. The presence of a cyst can provide an obstacle to the conventional orthodontic treatment given to the patients. The purpose of this article is to describe a case report of a seventeen year-old girl with a severe crowding of maxilla and presence of benign cyst between lateral incisor teeth and upper left canine treated with an alternative orthodontic treatment plan. After orthodontic diagnosis, the first treatment to be conducted was the removal of the cyst. The cyst was sent for biopsy and diagnosed as non-malignant cyst. The patient and her parents decided to extract upper laterals incisor tooth after knowing that the upper left lateral incisor tooth was necrotic. After the extractions, orthodontic brackets were bonded on the mandible. Then three months later the maxilla was bonded. The upper crowding of teeth condition was resolved very promptly and the upper canines were used to replace the laterals incisor position. Currently, active treatment is still in progress, and the patient has full upper and lower orthodontic brackets with class III elastics. After the treatment so far, it can be concluded that unconventional orthodontic treatment is worth considering when an obstacle such as a cyst is present. Patients and parents must be informed about the consequences of the treatment before active treatment is started.

Maj Ked Gi. Juni 2013;20(1): 99 - 104.
\end{abstract}

Keywords: crowding, upper teeth , benign cyst, unconventional orthodontic treatment

\section{PENDAHULUAN}

Perawatan ortodontik bertujuan untuk menghasilkan kondisi yang sehat, gigitan fungsional, ketahanan terhadap penyakit, dan penampilan personal. Hal ini memberikan kontribusi juga terhadap fisik dan mental seorang individu. Masalah yang umum terjadi adalah kondisi gigi berjejal berat.

Keberadaan kista dapat mengganggu atau mengubah rencana perawatan pasien secara keseluruhan. Maka dari itu, sangatlah penting untuk mendiagnosis keberadaan kista sesegera mungkin.
Kista dapat menyebabkan terlambatnya erupsi gigi, gigi berjejal atau mengganggu proses kesejajaran gigi, pembengkakan dan impaksi gigi. Kista perlu diangkat dan dilakukan biopsi. Hal tersebut perlu dilakukan sebelum perawatan ortodontik dimulai. Hasil biopsi sangat penting dalam menentukan apakah perawatan ortodontik dapat dilakukan. Jika kista cenderung menjadi ganas, maka pasien perlu menjalani beberapa perawatan terkait keberadaan kista. Jika kista merupakan lesi yang bersifat jinak, maka perawatan ortodontik dapat dilakukan. Tujuan 
Timothy S. dkk: Perawatan Ortodontik ...
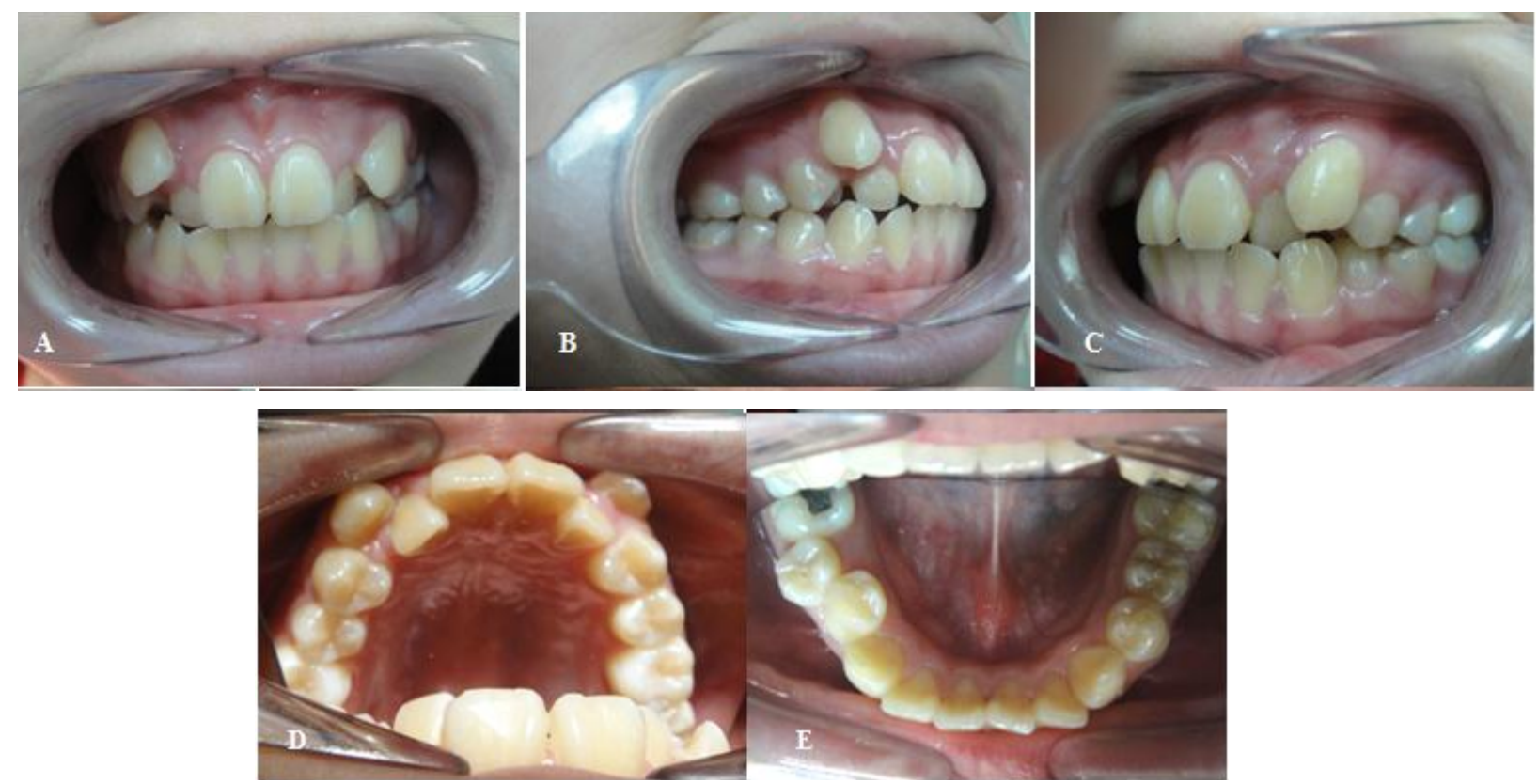

Gambar 1. Fotografi intraoral sebelum perawatan : A) Frontal; B) Sisi Kanan; C) Sisi Kiri; D) Oklusal Atas; E) Oklusal Bawah

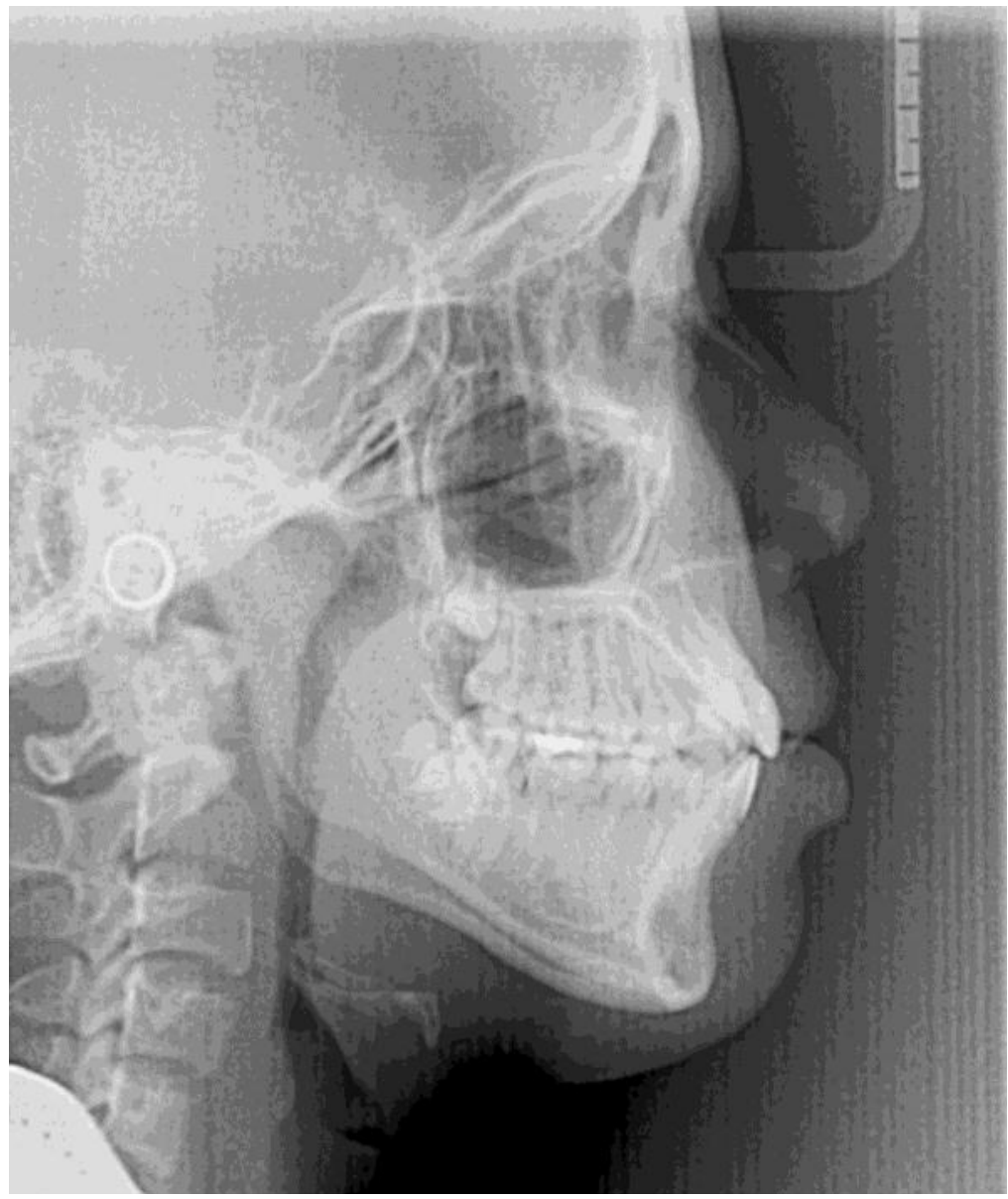

Gambar 2. Hasil rontgen sefalometri 


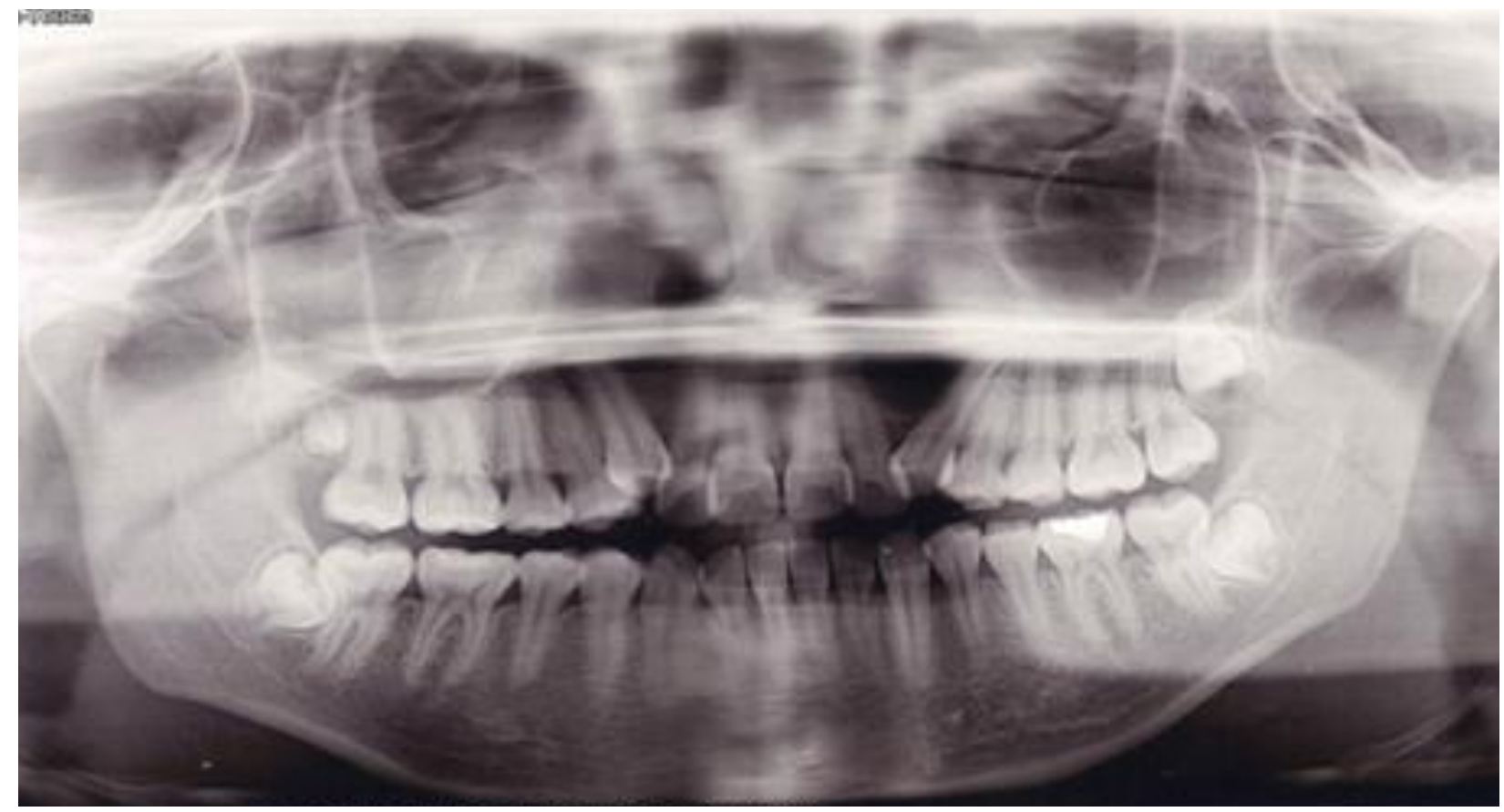

Gambar 3. Hasil rontgen panoramik

artikel ini adalah untuk memaparkan perawatan seorang perempuan berusia 17 tahun 10 bulan dengan maloklusi klas II dengan kondisi gigi atas berjejal berat dan kista jinak antara insisivus lateral dan kaninus kiri atas dirawat melalui pendekatan ortodontik inkonvensional.

\section{STUDI KASUS}

Seorang pasien perempuan berasal dari Cina, berusia 17 tahun 10 bulan, dirujuk dari dokter gigi untuk konsultasi perawatan ortodontik terkait kondisi gigi berjejalnya. Keluhan utamanya adalah ingin merapikan gigi depannya. Riwayat kesehatan umum dan dentalnya dalam batas normal.

Pemeriksaan intraoral menunjukkan bahwa pasien memiliki kondisi gigi atas berjejal berat dengan gigi kaninus berada di bagian bukal.

Kedua insisivus lateral menunjukkan relasi gigitan terbalik anterior. Relasi molar kanan klas II sedangkan molar kiri klas I (Gambar 1). Berdasarkan analisis sefalometri, pasien memiliki hubungan skeletal klas I dan hubungan molar klas II divisi 1 subdivisi (Gambar 2). Hasil rontgen panoramik dan periapikal menunjukkan bahwa terdapat lesi radiolusen antara kaninus kiri atas dan insisivus lateral (Gambar 3).

Rencana perawatan kasus ini didesain untuk mencapai tujuan klinis seperti pengangkatan kista, diagnosis kista melalui biopsi dan pencabutan dua gigi untuk memperbaiki kondisi gigi atas berjejal. Tahap pertama dalam perawatan adalah menginformasikan pasien dan orang tuanya mengenai keberadaan kista dan perlunya mengangkat kista tersebut sesegera mungkin. Tindakan bedah terhadap kista dilakukan dan spesimen dikirim untuk dilakukan biopsi (Gambar 4). Hasil biopsi mengindikasikan lesi bersifat jinak berupa kista radikuler dan tidak diperlukan perawatan terkait kista tersebut selain memonitor untuk mengetahui kejadian berulang (Gambar 5). Gigi insisivus lateral kiri atas dites dan hasil menunjukkan bahwa gigi tersebut nekrosis. Orang tua dan pasien memutuskan untuk mengambil gigi insisivus lateral daripada premolar pertama untuk memperoleh ruang dalam rangka merawat gigi yang berjejal. 


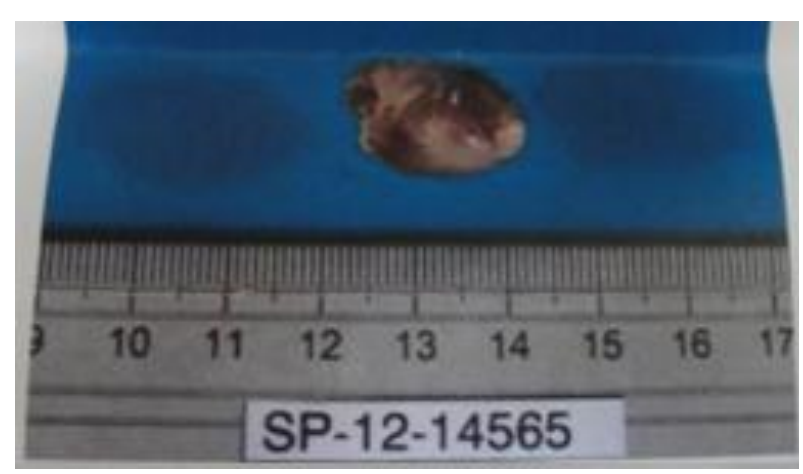

Gambar 4. Spesimen kista

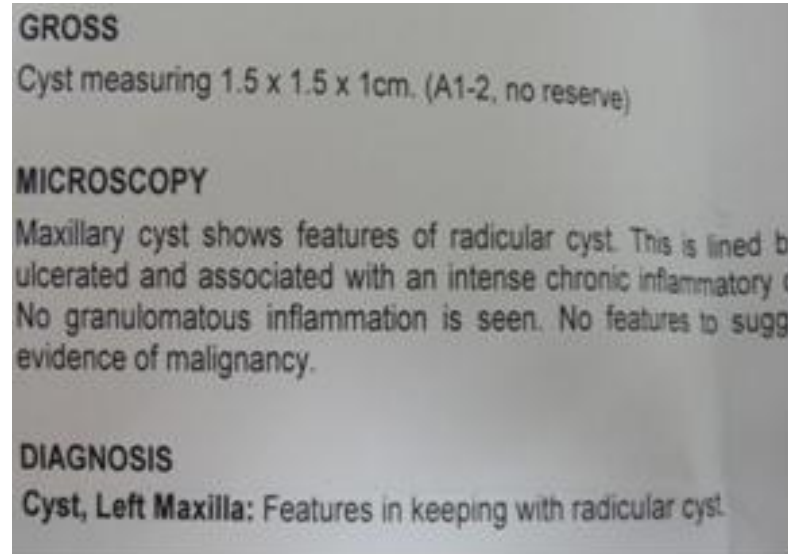

Gambar 5. Hasil biopsi menunjukkan Diagnosis kista
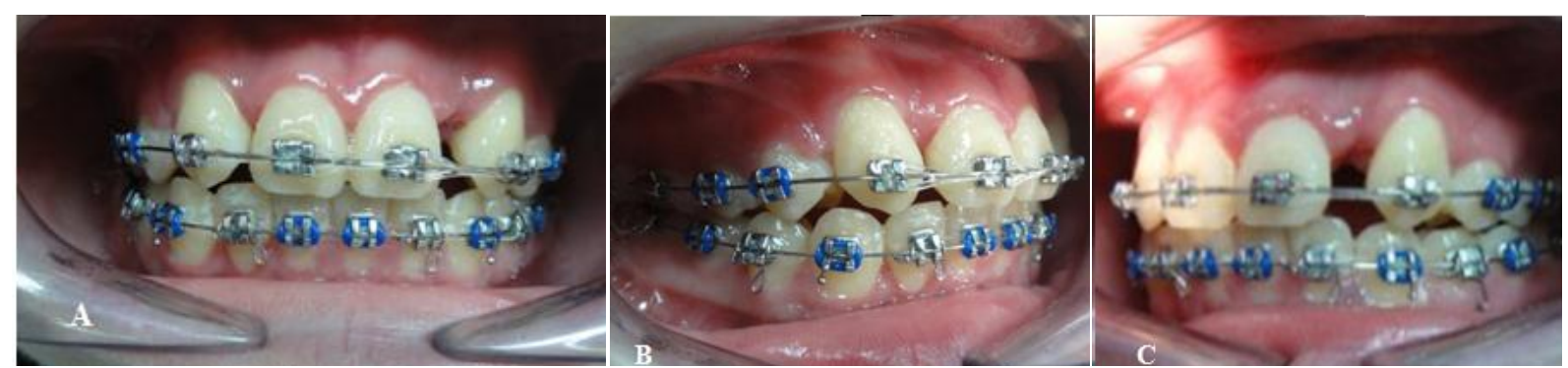

Gambar 6. Fotografi intraoral selama perawatan : A) Frontal; B) Sisi Kanan; C) Sisi Kiri

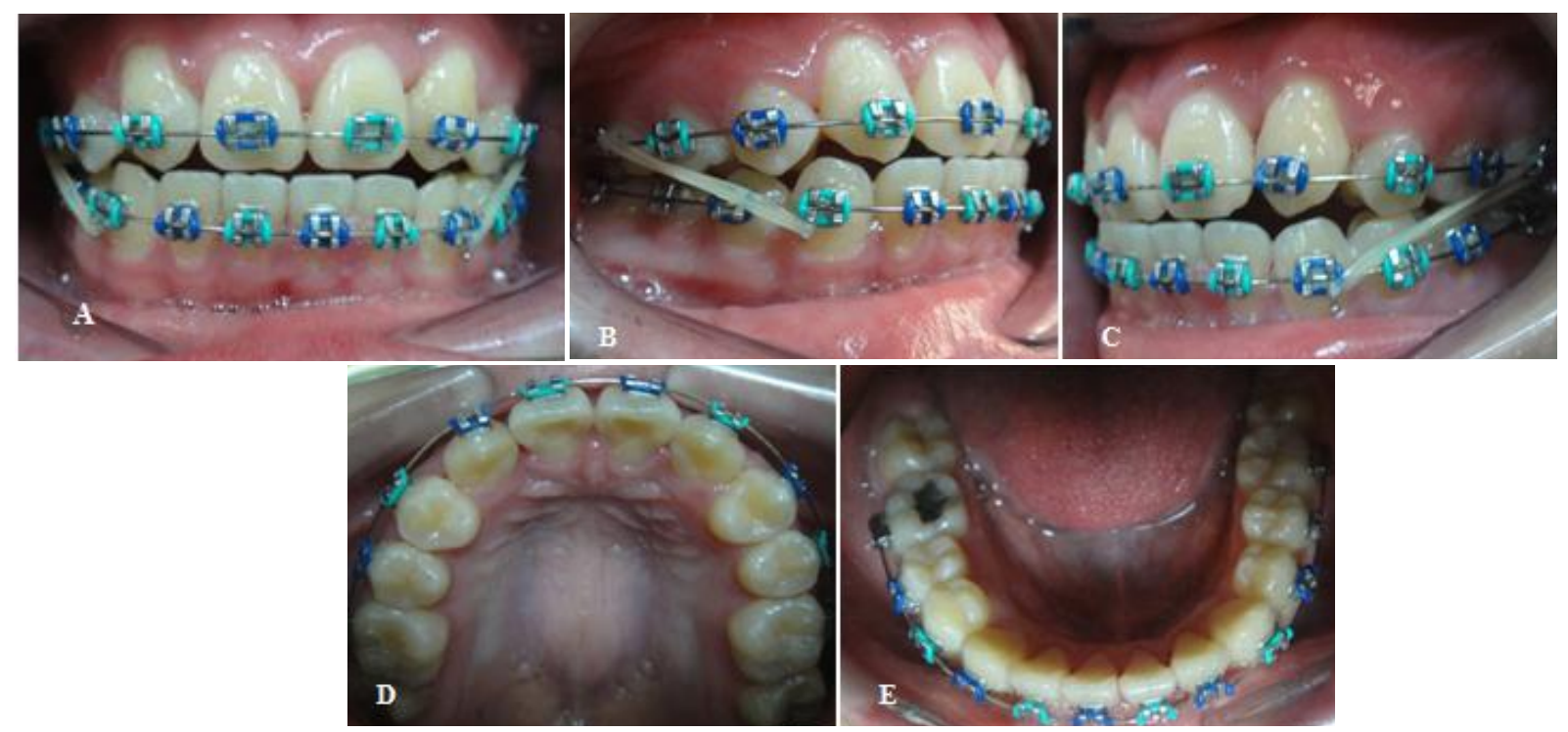

Gambar 7. Fotografi intraoral terakhir selama perawatan : a) Frontal; b) Sisi kanan; c) Sisi kiri; d) Oklusal atas; e) Oklusal bawah 
Kemudian, gigi bawah dirawat dengan memasang bracket slot ortodontik 0,022" dan perawatan ortodontik pada rahang bawah dimulai dengan pemasangan kawat NiTi 0.014". Pemasangan bracket pada gigi atas pasien dilakukan setelah 3 bulan untuk menunggu proses pemodelan ulang tulang sebelum perawatan ortodontik dimulai.

Kondisi gigi atas yang berjejal dirawat dengan kawat NiTi dan bantuan boks elastik. Gambar 6 menunjukkan bahwa kondisi gigi berjejal pada rahang atas maupun bawah telah terkoreksi. Saat ini, pasien masih melanjutkan perawatan ortodontik dengan elastik kelas III. Perawatan saat ini dilakukan untuk mengoreksi garis tengah dan oklusi lebih lanjut (Gambar 7).

\section{PEMBAHASAN}

Hasil pemeriksaan klinis dan cetakan pasien menunjukkan bahwa terdapat maloklusi disertai dengan gigi berjejal. Pencabutan gigi premolar atas menjadi suatu kebutuhan untuk merawat kasus tersebut. Hasil ronsen menunjukkan pula bahwa pasien memiliki lesi radiolusen antara insisivus lateral kiri atas dan kaninus kiri atas. Maka dari itu, pasien dan orang tuanya diberikan informasi mengenai lesi tersebut dan pasien dirujuk ke ahli bedah mulut untuk perawatan lebih lanjut. Pada kasus ini, tujuan perawatan menjadi lebih luas karena lesi perlu dirawat beserta maloklusi.

Lesi yang diduga sebagai kista sulit dievaluasi hanya dari gambaran radiologisnya saja. Diagnosis final harus dilakukan melalui pemeriksaan makroskopis dan mikroskopis karena terdapat kemiripan gambaran radiologis. ${ }^{1}$ Lesi radiolusen antara insisivus lateral kiri atas dan kaninus kiri atas pada kasus merupakan kista sehingga kista tersebut perlu diangkat dan dilakukan biopsi. Setelah pasien dan orang tua memberikan persetujuan atas rencana pengangkatan kista dan biopsi maka tindakan dapat dilakukan. Hasil biopsi mengindikasikan bahwa spesimen merupakan kista radikuler bersifat jinak seperti tampak pada Gambar 5.

Kista lebih sering ditemui di rahang daripada tulang lainnya karena keberadaan sisa epitel setelah odontogenesis. ${ }^{2.3}$ Kista radikuler adalah lesi kista yang sering ditemui di rahang (52-68\%). Kista ini umumnya ditemui di apeks gigi, namun juga dapat ditemukan di lateral akar sehubungan dengan adanya saluran akar tambahan. ${ }^{4}$ Gambaran radiologis kista radikuler adalah lesi radiolusen unilokuler berbentuk bulat atau seperti buah pir di area periapikal. Kista dapat menyebabkan perubahan letak gigi yang terlibat atau resorpsi akar ringan..$^{2,3}$

Kista ini berkembang ketika terjadi inflamasi pulpa yang menyebar hingga area periapikal atau lateral dan menyebabkan proliferasi sisa epitel Malassez di ligamen periodontal sehingga membentuk kavitas kista dikelilingi epitel. Insidensi tertinggi adalah regio anterior maksila. ${ }^{5}$ Pemeriksaan berikutnya menunjukkan pula bahwa gigi insisivus lateral kiri atas pasien nekrosis.

Pilihan perawatan untuk kista radikuler adalah perawatan saluran akar konvensional ketika lesi terjadi secara lokal atau tindakan bedah seperti enukleasi, marsupialisasi, atau dekompresi ketika ukuran lesi cukup besar. ${ }^{6}$ Kista yang tidak diambil dapat menyebabkan destruksi dan deformitas jaringan di sekitarnya. ${ }^{7}$ Kasus kista dirawat melalui ekstraksi gigi yang nonvital atau impaksi dan pengambilan kista melalui enukleasi. ${ }^{8}$ Karena lesi tersebut merupakan kista jinak, tidak diperlukan perawatan lebih lanjut setelah tindakan bedah selain memonitor untuk mengetahui kejadian berulang.

Semua tindakan kedokteran gigi, termasuk tindakan bedah dan perawatan ortodontik yang akan dilakukan terhadap pasien, harus mendapat persetujuan karena persetujuan tindakan kedokteran gigi merupakan proses sekaligus hasil dari suatu komunikasi yang efektif antara pasien dengan dokter gigi. Pada umumnya, seseorang dengan tanggung jawab orang tua dapat memberikan keputusan bagi anak-anak. Persetujuan ini diperoleh setelah pasien atau yang sah mewakilinya menerima informasi yang cukup untuk dapat membuat persetujuan. Informasi tersebut mencakup diagnosis dan tata cara tindakan medis, tujuan tindakan medis yang dilakukan, alternatif tindakan lain dan risikonya, risiko dan komplikasi yang mungkin terjadi, serta prognosis terhadap tindakan yang dilakukan. ${ }^{9}$ Rencana perawatan ortodontik berupa koreksi kondisi gigi atas yang berjejal ditawarkan kepada orang tua dan pasien pada kasus ini. Pilihan pertama 
adalah pencabutan gigi premolar pertama atas pasien sedangkan pilihan kedua adalah pencabutan gigi insisivus lateral atas karena hasil menunjukkan bahwa gigi insisivus lateral kiri atas nekrosis.

Orang tua dan pasien memilih pendekatan inkonvensional yaitu pencabutan gigi insisivus lateral atas untuk mengoreksi gigi atas yang berjejal. Orang tua menolak perawatan saluran akar yang dapat ditawarkan sebagai perawatan gigi insisivus lateral yang nekrosis. Orang tua dan pasien juga telah diberi informasi mengenai konsekuensi pilihan perawatan, seperti hasil akhir berupa posisi gigi kaninus yang menggantikan gigi insisivus lateral atas. Pasien juga memerlukan tindakan grinding atau perawatan restoratif pada gigi kaninus atas untuk meningkatkan penampilannya. Orang tua dan pasien menyatakan setuju setelah mengetahui segala konsekuensi dan risiko terhadap perawatan yang dilakukan.

Setelah dilakukan pencabutan terhadap insisivus lateral atas, gigi bawah pasien dirawat menggunakan bracket GAC dengan slot 0,022". Pemasangan bracket pada gigi atas pasien dilakukan setelah 3 bulan untuk menunggu proses remodeling tulang sebelum perawatan ortodontik dimulai. Remodeling tulang terjadi perlahan beberapa bulan hingga tahunan sehingga bentuk, struktur, dan kekuatan mekanisnya menyerupai tulang pada awalnya. Kekuatan optimal dicapai sekitar 3-6 bulan.$^{10}$

Tahap levelling dan aligning dengan kawat $\mathrm{NiTi}$ menjadi tahap awal perawatan ortodontik. Gambar 6 menunjukkan perkembangan perawatan setelah 5 bulan perawatan aktif berjalan. Gambar 7 menunjukkan hasil setelah 8 bulan perawatan aktif. Saat ini, pasien masih melanjutkan perawatan aktif untuk mengoreksi garis tengah dan hubungan gigi anterior yang edge to edge untuk memperoleh overjet dan overbite serta memperbaiki oklusi lebih lanjut. Upaya yang dapat dilakukan adalah penggunaan karet elastik dengan alternatif berupa pencabutan gigi bawah.

Pasien menjalani perawatan ortodontik dengan pendekatan inkonvensional karena keberadaan kista. Perawatan ortodontik pada kasus pasien termasuk perawatan inkonvensional karena gigi insisivus lateral atas dicabut, bukan pertama premolar atas. Gigi bawah pasien juga dirawat 3 bulan lebih awal daripada gigi atas. Namun demikian, sejauh ini pendekatan ini memberikan hasil yang sangat menjanjikan.

\section{KESIMPULAN}

Pendekatan perawatan ortodontik inkonvensional dapat menjadi pertimbangan ketika ditemukan hambatan seperti adanya kista. Pasien dan orang tua harus diberi informasi mengenai konsekuensi perawatan sebelum perawatan dimulai.

\section{DAFTAR PUSTAKA}

1. Scholl RJ, Kellett HM, Neumann DP, Lurie AG. Cysts and cystic lesions of the mandible: clinical and radiologic-histopathologic review. Radiographics, 1999; 19 : 1107-24.

2. Cawson RA, Odell EW, Porter S. Cawson's essentials of oral pathology and oral medicine. $7^{\text {th }}$ ed. Edinburgh: Churchill Livingstone; 2002. H. 102-21.

3. Regezi JA, Sciubba JJ, Jordan RCK. Oral Pathology: Clinical Pathologic Correlations. $4^{\text {th }}$ ed., WB Saunders. St Louis. 2003; 241-54.

4. Nair PNR. Non-Microbial Etiology: Periapical Cysts Sustain Post-Treatment Apical Periodontitis. Endodontic Topics. 2003; 6: 96-113.

5. Kramer LR, Pindborg JJ, Shear M. Histological Typing of Odontogenic Tumors. $2^{\text {nd }}$ ed., SpringerVerlag. Berlin. 1992; 41.

6. Ribeiro PD, Gonçalves ES, Neto ES. Surgical Approaches of Extensive Periapical Cyst : Considerations about Surgical Technique. Salusvita Bauru. 2004; 23: 317-28.

7. Riachi F, Tabarani C. Effective Management of Large Radicular Cysts Using Surgical Enucleation vs Marsupialization : Two Cases Report, IAJD, 2010; 1 (1) : 44-51.

8. Koseoglu BG, Atalay B, Erdem MA. Odontogenic Cysts: A Clinical Study of 90 Cases, J Oral Sci. 2004; 46 (4) : $253-7$.

9. Rafly A, Sampurna, B. Manual Persetujuan Tindakan Kedokteran. Konsil Kedokteran Indonesia. Jakarta Selatan. 2006; 1 - 21

10. Kalfas $\mathrm{IH}$. Principles of Bone Healing, Neurosurg Focus, $2001 ; 10$ (4) : 7 - 10. 